This PDF is a selection from a published volume from the National Bureau of Economic Research

Volume Title: Globalization and Poverty

Volume Author/Editor: Ann Harrison, editor

Volume Publisher: University of Chicago Press

Volume ISBN: 0-226-31794-3

Volume URL: http://www.nber.org/books/harr06-1

Conference Date: September 10-12, 2004

Publication Date: March 2007

Title: Risk and the Evolution of Inequality in China in an Era of Globalization

Author: Ethan Ligon

URL: http://www.nber.org/chapters/c0117 


\title{
Risk and the Evolution of Inequality in China in an Era of Globalization
}

\author{
Ethan Ligon
}

\subsection{Introduction}

Changes in poverty rates within a country, whether due to globalization or some other source, can be usefully thought of as reflecting either changes in aggregate resources (growth) for the country as a whole, or changes in the within-country distribution of these resources (inequality). Over the last twenty years China has experienced huge rates of economic growth, reducing poverty. Although at the same time China has experienced substantial increases in rural-urban and interregional inequality, the increase in the size of the Chinese economic pie has much more than offset any increase in inequality for the vast majority of China's households. Ravallion and Chen (2004) report that although 17.6 percent of Chinese households were poor in 1985, the poverty rate had fallen by more than half by 2001.

Faced with evidence of high rates of aggregate growth and relatively modest increases in inequality, and with evidence that poor households have shared in the aggregate windfall, one might be tempted to conclude that China's recent experience has had clear net benefits for almost all households. Yet this conclusion (while possibly correct) isn't justified by the kinds of evidence given above. The kinds of changes described above are likely to involve a large increase in the risk faced by Chinese households. Would a typical household in China in the early eighties, given a choice between their "iron rice bowl" and the risky promises of economic reform, have willingly chosen the latter? We can't know without some way 
of measuring the welfare costs of the increased risks actually borne by these households.

The welfare loss due to risk faced by households at a point in time is intimately related to changes in inequality in expenditures. In particular, risk-averse households with time-separable preferences will tend to prefer to smooth shocks to income over time, so that even entirely transitory shocks to income will tend to have a permanent effect on future consumption expenditures. Thus, the same shocks to income that make next period's consumption uncertain will also determine the household's position in next period's distribution of expenditures.

In this paper we exploit this link by using data on the evolution of expenditure inequality to estimate both household risk preferences and the welfare loss due to risk actually borne by urban Chinese households over the period 1985-2001, an era during which China's economy has undergone dramatic reforms and experienced remarkable growth. Others have noted that increases in inequality imply that the rising tide of the aggregate Chinese economy has not lifted all boats equally (Kahn and Riskin 2001). Here we note that because households may change their position in the wealth (and expenditure) distribution, merely looking at changes in inequality will understate the displacement and (ex ante) welfare loss experienced by risk-averse households facing dramatic economic change.

Although the chief contribution of this paper is the application of a method to infer household-level idiosyncratic risk from aggregate data on the cross-sectional distribution of consumption, it also has something to say about changes in inequality in the absence of this risk. In particular, we see that although there has been a notable increase in inequality among urban households, this increase is dwarfed by the increase in inequality between rural and urban households. We are also interested in documenting any relationship between globalization (as measured by changes in trade volume across sectors) and changes in urban inequality. In section 14.3 we show that after controlling for any effects that globalization may have on aggregate urban consumption the trade shocks we measure can't account for any of the observed changes in inequality observed within the urban population.

Models having complete markets à la Arrow-Debreu yield fully Pareto efficient outcomes; in such a model any changes in inequality must be preferred by all market participants, and so they yield little in terms of interesting policy implications. Complete market models that feature Gorman aggregable preferences (Wilson 1968) yield the very strong prediction that the distribution of consumption across households is invariant (see subsection 14.2.1 for an illustration and appendix A for a general treatment). More interesting are models in which some friction prevents allocations from being fully Pareto optimal, and that have enough dynamic structure to yield interesting predictions regarding the evolution of the distribution of consumption. 
To estimate the importance of idiosyncratic risk we assume that all households have similar preferences, and that these preferences exhibit constant relative risk aversion (Arrow 1964). We further assume that all households have access to credit markets on equal terms, and that households exploit these credit markets to smooth their consumption over time, à la the permanent income hypothesis. ${ }^{1}$ Beyond this, we make no notably restrictive assumptions. We allow quite arbitrary forms of technology and shocks, and avoid the problem of measuring asset returns. Although this framework is quite general in several dimensions, we will show that conditional on the distribution of production shocks the model yields rather sharp predictions regarding the evolution of the distribution of resources across households. In particular, the model gives us the law of motion governing the inverse Lorenz curves that describe inequality in the economy; the idiosyncratic risk borne by households can be shown to depend entirely on the distribution of "relative surprises" experienced by the household.

The law of motion for inverse Lorenz curves allows us to make predictions about the sequence of Lorenz curves we would expect to observe, conditional on household risk preferences, on rates of aggregate economic growth, and on the distribution of unforecastable shocks facing households in different years, at different wealth levels, and in different occupations. By comparing realized and predicted Lorenz curves, we can estimate these preferences and distributions. This same procedure yields a Markov transition function mapping shares of consumption today into a probability distribution over possible shares tomorrow, and we use this object to calculate the risk borne by differently situated urban Chinese households in different years and to relate this risk to measures of globalization during this period.

The key to the empirical strategy of this paper involves exploiting the restrictions placed on data by Euler equations to make statements about the evolution of inequality. Related literature includes Deaton and Paxson (1994), who derive a martingale property from the consumption Euler equation and use several long panels of household-level expenditure data to argue that within-cohort inequality in industrialized countries is increasing over time, and Storesletten, Telmer, and Yaron (2004), who use household panel data on expenditures from the United States and a more completely specified general equilibrium model to estimate a law of motion for the distribution of consumption. The central idea of those papers is to exploit intertemporal restrictions to estimate the law of motion for individual households' consumption growth, and then in effect to integrate over households to infer what the law of motion is for the distribution of

1. For the reader who regards this assumption as unreasonable, we note that if some households are constrained so as to not have equal access to credit markets, then our estimates of risk for these households are likely to be underestimates. 
consumption across households. The present paper reverses these last two steps - we derive equations that impose intertemporal restrictions on individual households' consumption growth, but then integrate over these equations to obtain restrictions on the law of motion for the distribution of consumption across households before taking these restrictions to the data. The cost of the procedure followed in this paper is that one can't exploit all the information that would be available from the trajectories of consumption for many different individual households. The (closely related) benefit is that we can get by without panel data, using instead only a relatively limited set of data obtainable from repeated cross-sectional surveys of household expenditures, of the sort that many countries conduct in order, for example, to compute consumer price indexes.

\subsection{An Example of Risk and Inequality}

The central idea of this paper is to use evidence on changes in the crosssectional distribution of consumption to draw inferences about the welfare of households. In this section we'll construct a simple example, meant to illustrate the connection between the evolution of inequality and household welfare, while appendix A provides a more general treatment. As will be seen, the connection between household welfare and changes in inequality can be more complicated and interesting than one might suppose.

To set the stage for our example, consider an environment with many households, but only two types (each type comprising one-half of the population), indexed by $i=1,2$. There are two periods, indexed by $t=1,2$. Households of both types derive momentary utility from consumption according to a logarithmic utility function:

$$
u\left(c_{i t}\right)=\log \left(c_{i t}\right) .
$$

Both types of households also discount future utility using a common discount factor, $\beta \in(0,1)$.

Critical to the example is that there be some source of underlying uncertainty that may affect the second-period distribution of consumption. Let $\omega \in \Omega$ denote the realized state of the economy in this second period. Assuming $\Omega$ is finite, let $\operatorname{Pr}(\omega)$ denote the probability of state $\omega$ being realized.

Per capita consumption in period $t$ is some exogenously determined (but possibly random) quantity $\bar{c}_{t}$; we choose a normalization for consumption so that $\bar{c}_{1}=1$. The characteristic that distinguishes the two different types of households is that each type begins with different shares of aggregate consumption. In particular, let the consumption of type 1 households in period 1 be $c_{11}=0.4$, so that consumption of the second type is $c_{21}=0.6$.

We now consider three different market structures and ask how these influence the evolution of inequality. 


\subsubsection{Complete Markets}

When there are complete markets, we can exploit the second welfare theorem to compute changes in inequality for our example economy. Accordingly, consider the planning problem of allocating consumption across representative households of each type,

$$
\begin{aligned}
\max _{\left\{c_{i 1},\left\{c_{i 2}(\omega)\right\}_{\omega \in \Omega}\right\}_{i}} \sigma u\left(c_{11}\right)+(1 & -\sigma) u\left(c_{21}\right) \\
& +\beta \sum_{\omega \in \Omega} \operatorname{Pr}(\omega)\left\{\sigma u\left[c_{11}(\omega)\right]+(1-\sigma) u\left[c_{22}(\omega)\right]\right\},
\end{aligned}
$$

subject to resource constraints in each period,

$$
c_{11}+c_{21} \leq \bar{c}_{1},
$$

and

$$
c_{12}(\omega)+c_{22}(\omega) \leq \bar{c}_{2}(\omega) .
$$

Here the parameter $\sigma$ is a "planning weight" that determines the weight of type one households relative to type two in the planner's problem. With the form of utility function assumed above, it follows immediately from the first-order conditions that

$$
c_{11}=\sigma \bar{c}_{1}
$$

and

$$
c_{12}=\sigma \bar{c}_{2}(\omega) .
$$

Note from this that the parameter $\sigma$ corresponds to the share of aggregate consumption for type 1 households, and that this parameter doesn't vary across either dates or states. As a consequence, any Pareto efficient outcome in this example will assign 40 percent (the share of type one households in the initial period) of aggregate consumption to households of type one in both periods, regardless of the realized value of $\omega$.

This point generalizes. When households have identical utility functions featuring constant elasticities of substitution (of which logarithmic utility is a special case) and when markets are complete, then we should expect the distribution of consumption to be unchanging. Conversely, if the distribution of consumption is observed to change over time, then this is evidence that either our assumptions regarding household preferences are mistaken or markets are incomplete (Lucas 1992).

\subsubsection{Segmented Markets}

Taking our cue from subsection 14.2.1, we next imagine a particular sort of simple market incompleteness that can give rise to nontrivial changes in 
consumption inequality. In particular, suppose that although households of type $i$ can engage in exchange with other households of the same type, circumstances contrive to make it impossible for households of type 1 to make exchanges with households of type 2 . Thus, a social planner must keep track of aggregate resources available to households of each type. Within the set of type $i$ households there will be perfect insurance, so we can write $c_{i 2}(\omega)=\bar{c}_{i 2}(\omega)$, where $\bar{c}_{i 2}(\omega)$ is the per capita consumption available to households of type $i$ in state $\omega$.

To be concrete, suppose that the share of type 1 households happens to fall from 0.4 in the first period to 0.3 in the second, but that total consumption across both groups remains constant. Then the ex post welfare outcome for each household type relative to the complete markets case is the same in the first period, but in the second the difference is given by

$$
\begin{aligned}
& \log (0.3)-\log (0.4) \approx-0.288 \\
& \log (0.7)-\log (0.6) \approx 0.154 .
\end{aligned}
$$

Though very contrived, this accounting seems to capture the usual idea behind analyses of changes in inequality - in this case, poor households (type 1) are hurt by an increase in inequality, while wealthy households (type 2) fare better. The chief point missed by this idea is that in the face of uninsured shocks individual households are likely to change their position in the consumption distribution.

\subsubsection{Credit Markets}

We next eliminate the supposition of segmented markets and suppose that households of both types can exchange debt in competitive credit markets. However, for whatever reason, we also suppose that households can't perfectly insure their future consumption, as they did in subsection 14.2.1. We then derive intertemporal restrictions on the evolution of each household's share of aggregate consumption. The key assumptions we exploit here (and later in our empirical work) are that households all have similar preferences featuring constant relative risk aversion, and that all households have access to credit on the same terms. Note that this latter assumption is weaker than assuming that credit markets are perfect-in particular, it may be the case that at the interest rates faced by households for some reason credit markets fail to clear.

At date 1, households of each type can exchange claims to consumption at date 2 with other households at a price $\beta$, solving the problem

$$
\max _{b_{i}} u\left(c_{i 1}-b_{i} \beta\right)+\beta E u\left(c_{i 2}+b_{i}\right) \text {, }
$$

where $\mathrm{E}$ denotes the expectations operator conditional on information available at time $1, b_{i}$ denotes the debt issued by a household of type $i$ in the first period, and $c_{i t}$ denotes the household's time $t$ consumption expenditures.

We modify our notation slightly to let the index $i$ refer to individual 
households $i=1, \ldots, n$, while maintaining our assumption that all of these households are of one of two distinct types. The modification is necessary because we want to consider the possibility that households of the same type may face different shocks, even though the distribution of these shocks will be the same for all households of the same type ex ante.

The first-order conditions associated with the household's problem of debt issuance indicate that the household will consume $c_{i t}$ at $t$ if the usual Euler equation

$$
u^{\prime}\left(c_{i t}\right)=\mathrm{E} u^{\prime}\left(c_{i t+1}\right)
$$

is satisfied.

Exploiting our assumption of logarithmic utility, equation (5) implies that

$$
1=\mathrm{E}\left(\frac{c_{i 1}}{c_{i 2}}\right)
$$

for $i=1,2, \ldots, n$.

Let

$$
\varepsilon_{i}=\left(\frac{c_{i 1}}{c_{i 2}}\right)-1
$$

denote household $i$ 's time 1 forecast error. Note from the properties of equation (6) that $E \varepsilon_{i}=0$, as is usual when evaluating forecast errors from Euler equations. Note also from equation (5) and Jensen's inequality we have $c_{i 1} / \mathrm{E} c_{i 2} \leq 1$, so that

$$
\mathrm{E} c_{i 2} \geq c_{i 1} ;
$$

that is, expected consumption is increasing for both types of households.

Risk

The risk facing any individual household with consumption $c_{i t}$ at time $t$ that may reduce its utility at time $t+1$ depends on the distribution on the forecast error $\varepsilon_{i}$.

Let $\sigma_{i t}$ denote household $i$ 's consumption share at date $t$. Define the idiosyncratic risk borne by the household at time 1 to be the ex ante loss in expected utility due solely to variation in the purely idiosyncratic shock $\varepsilon_{i}$, or

$$
R_{i} \equiv u\left(\bar{c}_{2} \sigma_{i 1}\right)-\mathrm{E}\left[u_{i}\left(c_{i 2}\right)\right] .
$$

Here the first term is the utility the household would obtain in period 2 if the household's share of expenditures was unchanged (as would be the case if no household faced any idiosyncratic risk) and if the household knew in advance what aggregate consumption would be in period 2 . The second term is the expected utility of the household given that it remained ignorant of the idiosyncratic shocks it would experience. 
As demonstrated above, in a world with complete markets and the assumed logarithmic preferences we work with here, it's easy to establish that each household's share of aggregate consumption will remain constant, eliminating all idiosyncratic risk. Thus, we can interpret the first term of equation (7) as the utility the household would obtain if no households bore any idiosyncratic risk less the expected utility of consumption when the household does bear this risk. It's trivial to establish that this cardinal measure of risk is uniquely consistent (up to a linear transformation of $u$ ) with the notion of increasing risk defined by Rothschild and Stiglitz (1970). Because our measure of idiosyncratic risk is denominated in utils, it is straightforward to construct a variety of useful measures of the welfare loss associated with this risk.

Again, for the sake of concreteness, let us assume that $\log \left(1+\varepsilon_{i}\right)$ is distributed $N\left(-v_{i}^{2} / 2, v_{i}\right)$, with the consequence that $\mathrm{E} \varepsilon_{i}=0$, as is required by our definition of the forecast error above, with $v_{i}$ a parameter equal to the standard deviation of $\log \left(1+\varepsilon_{i}\right)$ for household $i$. With this assumption it follows that household $i$ 's idiosyncratic risk (that is, holding aggregate consumption constant) is given by

$$
R_{i}=\frac{v_{i}^{2}}{2} .
$$

Thus the ex ante welfare loss due to the uninsurability of idiosyncratic shocks is simply equal to one-half the variance of $\log \left(1+\varepsilon_{i}\right)$.

\section{Distribution}

Now, how is this risk related to the evolution of inequality? Let $\Psi\left(\sigma_{i 2} \mid \sigma_{i 1}\right)$ denote the Markov transition function for the household's share $\sigma$ between periods 1 and 2. Then the expression for household $i$ 's time $t$ idiosyncratic risk, as defined above, may be written

$$
R_{i}=u\left(\bar{c}_{2} \sigma_{i 1}\right)-\int u\left(\bar{c}_{2} \sigma^{\prime}\right) d \Psi\left(\sigma^{\prime} \mid \sigma_{i 1}\right) .
$$

We've already seen that we can compute risk $R_{i}$ from knowledge of the distribution of $i$ 's forecast errors $\varepsilon_{i}$, so this equation allows us to relate the transition function $\Psi$ to the parameters of this distribution.

The Markov transition function $\Psi$, which is critical for calculating average risk in the population, is also critical for understanding how the distribution of resources changes over time. In particular, the distribution of consumption shares (inverse Lorenz curves) $\left\{\Gamma_{t}\right\}$ will satisfy a law of motion

$$
\Gamma_{2}(\hat{\sigma})=\int_{\left\{\sigma^{\prime}<\hat{\sigma}\right\}} d \Psi\left(\sigma^{\prime} \mid \sigma\right) d \Gamma_{1}(\sigma) .
$$

Accordingly, knowledge of the transition function $\Psi$ suffices to characterize both average risk and the evolution of inequality in the population.

Let us now discuss how knowledge of the cross-sectional distribution of 
consumption can be used to draw inferences about household-level risk. Recall that an individual household's risk depends only on forecast errors $\varepsilon_{i}$. In particular, we can use equation (6) to express $\Psi$ in terms of the distribution of forecast errors in the population. Let $\varepsilon_{i}$ have the cumulative probability distribution $F\left(\varepsilon \mid \sigma_{i}\right)$. Then equation (6) implies

$$
c_{i 2}=c_{i 1}\left(1+\varepsilon_{i t+1}\right)^{-1},
$$

so that, conditioning on consumption growth $g=\bar{c}_{2} / \bar{c}_{1}$,

$$
\Psi\left(\sigma^{\prime} \mid \sigma\right)=\int_{\left\{\varepsilon>\left[\left(\sigma / \sigma^{\prime}\right)-1\right] / g\right\}} d F(\varepsilon \mid \sigma) .
$$

Now, let us suppose that the change in the distribution of consumption is as above in subsection 14.2.2. In particular, the share of the bottom 50 percent of households falls from 40 percent in the first period to 30 percent in the second. We maintain our assumption that (one plus) forecast errors are distributed log normal and that these forecast errors have mean zero. We also maintain our assumption that the two different types of households are ex ante identical, and use the change in the distribution of consumption to infer the parameters $v_{i}$ that govern the distribution of forecast errors and risk borne by the households.

Using equations (8) and (10) it is straightforward to compute (see appendix B) the values of $v_{i}$ implied by this change in distribution. In particular, households of type 1 will have $v_{i} 0.267$, while households of type 2 will have $v_{i}$ of 0.55 . As an immediate consequence the risk borne by poor households will be equal to 0.0385 , while the risk borne by wealthy households will be equal to 0.1540 (bear in mind that these risk figures are denominated in utils).

The quite surprising result is that the apparent increase in wealthy households' share of consumption from 60 to 70 percent on average hurts the households that were wealthy ex ante. The cross-sectional distribution of consumption can't change unless at least some households face some idiosyncratic risk, and the only way to get the share of ex post wealthy households to increase is to expose all ex ante wealthy (type 2) households to a great deal of risk. As a consequence, even though expected consumption is increasing for all households, for type 2 households the probability of having a big drop in consumption offsets the expected consumption increase. Figure 14.1 shows the distribution of period $2 \log$ consumption for each of the two household types. Note that although the mean of the type 2 distribution is still greater than the mean of the type 1 distribution, the much greater variance in outcomes for the initially wealthier households means that some of these households will be at the very bottom of the consumption distribution in period 2.

This apparently perverse result depends less on the details of our quite special example than one might suppose. As long as preferences exhibit decreasing absolute risk aversion, it will be the initially wealthy households 


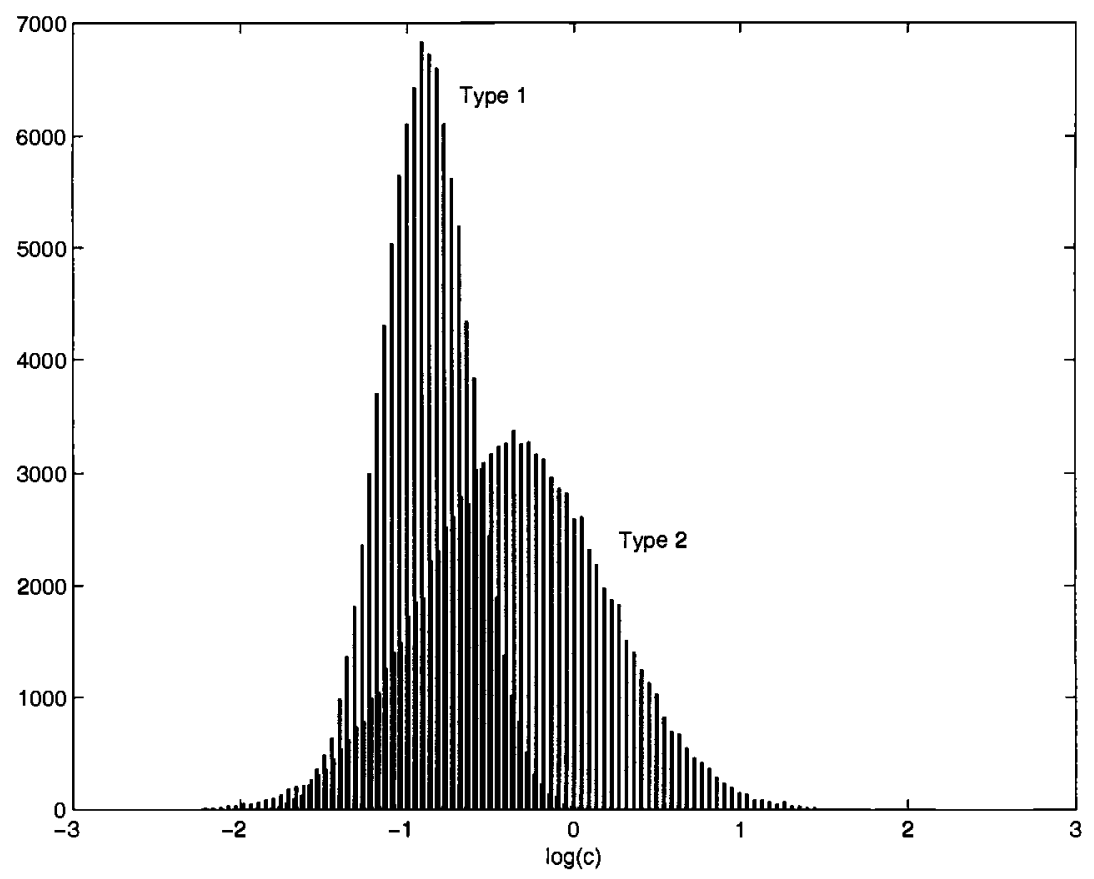

Fig. 14.1 Distribution of log consumption for different household types implied by shift in Lorenz curve

that will choose to take larger risks. Thus, big falls in the share of the bottom consumption quantile are likely to be due to some previously wealthy households having very bad luck, while a larger share of previously poor households will move into higher quantiles. In the example just presented, the matrix governing the transition between the bottom 50 percent and the top 50 percent turns out to be

$$
\left(\begin{array}{ll}
0.88 & 0.12 \\
0.06 & 0.94
\end{array}\right)
$$

Accordingly, we can see that 12 percent of type 1 households move up into the top quantile, while 6 percent of type 2 households fall down into the bottom quantile. The basic flavor of the result seems to depend only on decreasing absolute risk aversion and common access to credit markets. With these two ingredients apparent increases in inequality may actually imply that ex ante wealthy households are bearing large amounts of risk that often cast them far down the consumption distribution. 


\subsection{The Data}

We next turn to an application of some of the ideas developed in the preceding example and make an effort to draw inferences regarding the risk borne by households in China from data from the sequence of Lorenz curves describing the evolution of consumption inequality in China over the period 1985-2001.

In this section we document a few basic facts about Chinese inequality and then assume a structure similar to that of subsection 14.2.2, so that households within a population quantile stay within that quantile, sharing the variable consumption that accrues to the quantile. In a later section we instead assume equal access to credit markets and then use variation in Lorenz curves to draw inferences about idiosyncratic risk.

\subsubsection{Chinese Inequality}

Numerous authors have documented notable increases in inequality within China over the last two decades, although over the same period there has been a dramatic increase in aggregate consumption.

There are two observations about changes in Chinese inequality that seem to qualify as stylized facts. The first is that there have been large increases in the difference between rural and urban incomes over the last twenty years, while the second is that there has been increasing inequality in income across regions (especially between the coastal and interior areas).

In support of the first observation, Kahn and Riskin (2001) document notable increases in income inequality between rural and urban households over the period 1988-95. Ravallion (2004) and Chen and Ravallion (2004) explain part of this increase in urban-rural inequality by computing the effects of World Trade Organization (WTO) accession on rural and urban poverty, finding that on average rural households tend to lose due to decreases in the price of their mostly agricultural output, while urban consumers gain.

In support of the second observation, a number of authors have documented notable increases in regional inequality. Yang (1997) documents large shifts in the resources transferred between coastal and interior regions, and argues that such shifts entail increased regional inequality as a consequence. While using data on outcomes, Yao and Zhang (2001) document increases in interprovincial inequality, and posit the existence of "clubs" of provinces with incomes diverging from the incomes of other clubs.

Of course, even if both these observations are true, it may be the case that one observation is a consequence of the other. In particular, since there is wide variation in the proportion of rural households across provinces, it 
may well be the case that the observed increase in inequality across regions is simply a consequence of increased rural-urban inequality. Bhalla, Yao, and Zhang (2003) and Kanbur and Zhang (2005) use data on provincelevel incomes to argue that most inequality is due to rural-urban differences rather than to provincial-level differences; however, both papers still find a large role for provincial differences even after accounting for differences in rural-urban composition.

The general connection between trade and inequality (or poverty) discussed by Chen and Ravallion (2004) can also be found using much more aggregate provincial-level data. Kanbur and Zhang (2005) find that increases in interprovincial income inequality over time are associated with differences in openness, while Zhang and Zhang (2003) decompose a Theil measure of inequality and find that 20 percent of differences in per capita gross domestic product (GDP) across provinces in 1995 can be attributed to measures of trade (Milanovic 2005 shows that it is critical to weight provinces by population to obtain this result). However, as Ravallion (2004) cautions, this kind of association between two endogenous aggregates (inequality and trade) doesn't allow us to draw any inference about cause.

In an important reminder that inequality isn't mostly about aggregates, Benjamin, Brandt, and Giles (2005) examine a large panel of rural Chinese households and find evidence of larger increases in inequality within small geographical regions than across them.

\subsubsection{Urban Inequality}

Against this background of rapid increases in overall Chinese inequality, how should we assess changes in urban inequality? The way in which inequality changes over time matters greatly for evaluating household welfare. If all the increase in inequality is due to increases in equality between different groups, then the idiosyncratic risk due to this increasing inequality will be small. For example, one of the key features of Chinese reform has to do with the fact that reform began in the countryside, with the establishment of the household responsibility system in the late 1970s and the corresponding introduction of market prices (at the margin) for agricultural goods. These reforms ushered in a decade of rapid rural economic growth. The nineties brought an important change. A decade of rural growth was followed by an extended period of urban growth and relative rural stagnation. Yang (1997) argues convincingly that this shift was due to quite conscious and quite visible policy choices made by the central government, which exploited its control of nonagricultural prices to implicitly tax the interior of the country and to use the proceeds of these implicit taxes to finance investment in coastal urban areas. To the extent that one could predict that urban households would benefit from these policies at the expense of rural households, neither urban nor rural households would 
face any risk subsequent to this policy shift, but simply different expected growth trajectories.

Since the focus of this paper is on urban households, let us henceforth set aside changes in overall inequality due to the well-documented divergence in the consumption expenditures of rural and urban China. Instead, let us ask what our data can tell us about the evolution of inequality among urban Chinese households.

At the beginning of the period for which we have data, inequality in China was remarkably low. Although one still does not observe gross inequities in the distribution of consumption in China, over the course of 1985-2001 one does observe an increase in urban inequality. This point is made most clearly by figure 14.2. This figure shows the change in Lorenz curves for urban consumption over the period 1985-2001. Individual changes are shown year by year. It is apparent from these that inequality is not always increasing - from year to year one sees increases in equality with almost the same frequency as decreases. However, the average decrease in equality is larger than the average increase, with the consequence that when we aggregate all these changes, we see that the total change in Lorenz curves is considerable, with the bottom 60 percent of the distribu-

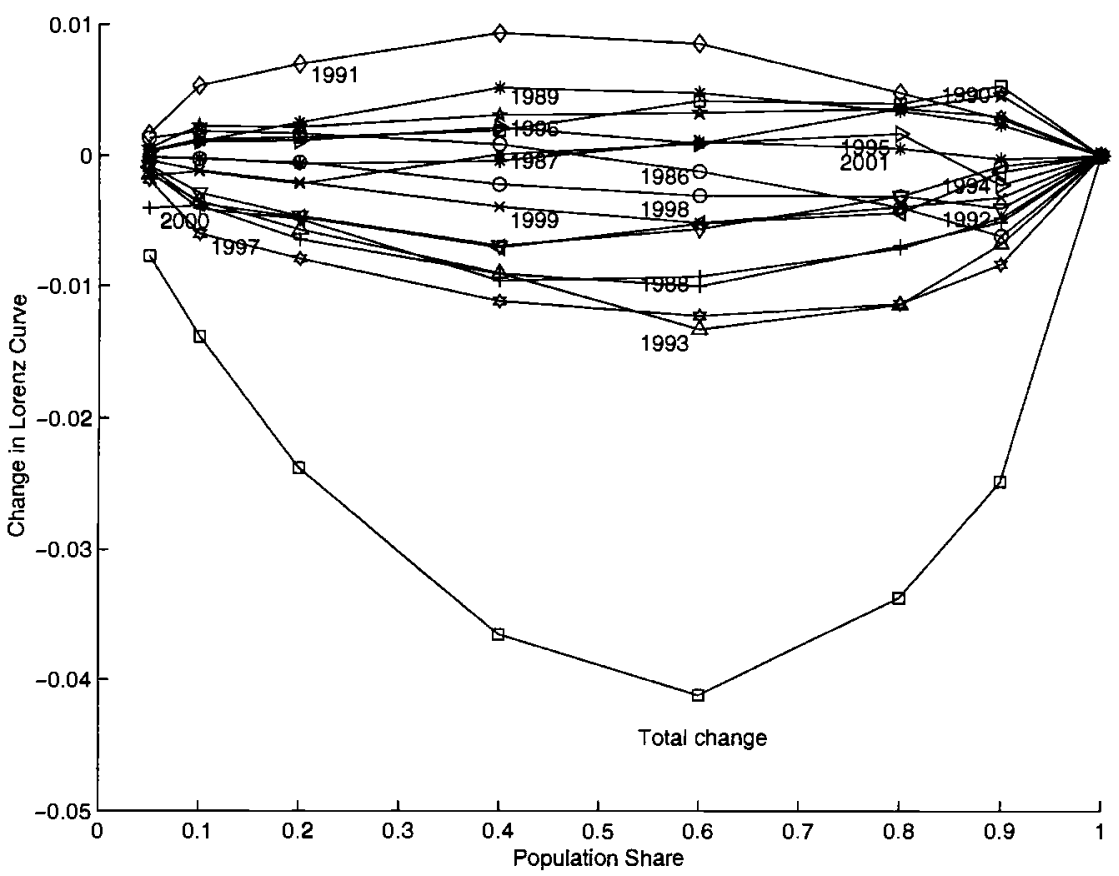

Fig. 14.2 Changes in consumption Lorenz curves for registered urban households 
Table 14.1 Increasing inequality?

\begin{tabular}{lrrrrrrrr}
\hline Quartile & $5 \%$ & $10 \%$ & $20 \%$ & $40 \%$ & $60 \%$ & $80 \%$ & $90 \%$ & $100 \%$ \\
\hline Growth rate & 0.123 & 0.117 & 0.112 & 0.117 & 0.110 & 0.128 & 0.133 & 0.113 \\
$t$-statistic & 5.064 & 4.786 & 4.593 & 4.816 & 4.531 & 5.272 & 5.440 & 4.629 \\
$5 \%$ & 0.000 & 0.197 & 0.333 & 0.176 & 0.377 & -0.146 & -0.266 & 0.308 \\
$10 \%$ & -0.197 & 0.000 & 0.136 & -0.021 & 0.180 & -0.344 & -0.463 & 0.111 \\
$20 \%$ & -0.333 & -0.136 & 0.000 & -0.157 & 0.044 & -0.480 & -0.599 & -0.025 \\
$40 \%$ & -0.176 & 0.021 & 0.157 & 0.000 & 0.201 & -0.322 & -0.442 & 0.132 \\
$60 \%$ & -0.377 & -0.180 & -0.044 & -0.201 & 0.000 & -0.523 & -0.643 & -0.069 \\
$80 \%$ & 0.146 & 0.344 & 0.480 & 0.322 & 0.523 & 0.000 & -0.119 & 0.454 \\
$90 \%$ & 0.266 & 0.463 & 0.599 & 0.442 & 0.643 & 0.119 & 0.000 & 0.574 \\
$100 \%$ & -0.308 & -0.111 & 0.025 & -0.132 & 0.069 & -0.454 & -0.574 & 0.000 \\
\hline
\end{tabular}

Notes: Average growth rates of consumption expenditures for different quantiles of the consumption distribution appear in the first row of the table, with $t$-statistics for these point estimates immediately below. The remaining rows of the table present $t$-tests of differences among the growth rates of different quantiles.

tion seeing a fall in its aggregate share of consumption of about 4 percent. The bottom 10 percent of the distribution sees a much larger (proportional) drop, with its share falling from about 8 percent in 1985 to about 6.5 percent in 2001, or a nearly 20 percent fall. Of course, as we see in table 14.1, this same bottom 10 percent has seen large increases in total consumption, so this fall in share has been much more than offset by increases in aggregate consumption.

We tackle the measurement of changes in urban inequality in two stages. First, we use aggregate data on the distribution of consumption expenditures to characterize changes in welfare and inequality across consumption quartiles. Subsequently we turn our attention to the problem of inferring the distribution of possible consumption outcomes for individual households at different points in the cross-sectional consumption distribution. We will use the inferences so drawn to quantify the idiosyncratic risk borne by these households.

We begin by trying to understand consumption growth by population quantile. Table 14.1 reports the average rate of consumption growth for each of eight quantiles over the period 1986-2001. The results of this exercise show that, when averaged over this entire period, there is remarkably little difference in the average rate of consumption growth for different quantiles. All of the eight quantiles have consumption growth that averages about 12 percent per year, and no quantile has a rate of growth significantly greater than that of any other quantile.

Of course, the fact that different quantiles all have roughly the same rate of consumption growth over a long period doesn't imply that there aren't differences over shorter periods. Accordingly, we next ask about how much of the variation in individual quantiles' consumption can be explained by 
Table 14.2

Analysis of variance of consumption growth

\begin{tabular}{lccc}
\hline Variables & Individual contribution $\left(R^{2}\right)$ & Cumulative contribution $\left(R^{2}\right)$ & $p$-value \\
\hline Quantile & 0.008 & 0.008 & 0.998 \\
Country shocks & 0.893 & 0.901 & 0.000 \\
Import shocks & 0.496 & 0.963 & 0.998 \\
\hline
\end{tabular}

Table 14.3

Decomposition of risk across quantiles

\begin{tabular}{lccc}
\hline & \multicolumn{3}{c}{ Sources of risk } \\
\cline { 2 - 4 } Risk & Country & Trade & Quantile risk \\
\hline $5 \%$ & 0.249 & 0.323 & 1.664 \\
$10 \%$ & 0.003 & 0.196 & 2.703 \\
$20 \%$ & 0.139 & 0.101 & 1.894 \\
$40 \%$ & 0.117 & -0.070 & 1.969 \\
$60 \%$ & 0.002 & -0.030 & 2.372 \\
$80 \%$ & 0.171 & -0.062 & 1.548 \\
$90 \%$ & 0.069 & -0.111 & 2.080 \\
$100 \%$ & 0.057 & -0.182 & 1.779 \\
\hline
\end{tabular}

Note: These figures do not include estimates of the risk due to idiosyncratic shocks.

country-level shocks. We begin by asking what proportion of quantiles' consumption growth is attributable to aggregate growth. These results are reported in the first row of table 14.2. We see from this that nearly 90 percent of variation in quantile consumption is due entirely to aggregate variation.

Finally, table 14.3 displays estimates of the welfare loss for households due to aggregate sources of risk (risk shared by all households in the country, quantile-level risk related to trade shocks, and residual quantile-level risk). All measures are denominated in utils and are computed in a manner analogous to the approach taken by Ligon and Schechter (2003). Note, however, that these measures of risk completely neglect idiosyncratic factors. Inferring this idiosyncratic component is the chief task of the remainder of this paper.

\subsection{Idiosyncratic Risk}

In this section we use the logic developed in the example of section 14.2 to draw inferences about the level of idiosyncratic risk from a sequence of Lorenz curves. We relax many of the most restrictive assumptions of the example, developing a more general framework for inference in appendix A and appendix B. One useful generalization involves giving a parametric form for the variance (or scale) that governs risk, permitting this variance 
to depend on a variety of observable variables. The general form for this scale parameter is given by equation (21).

\subsubsection{Error Components Structure}

We begin (adapting some language from Amemiya 1984) with a simple "error components" structure, permitting the log of the variance of the relative forecast error to depend on the sum of a year-specific constant and a quantile-specific constant, so that

$$
\log v_{i t}=\alpha_{i}+v_{t} .
$$

Here $v_{i t}$ is the standard error of the relative forecast shock for a household in the $i$ th quantile of the consumption share distribution in year $y$; in practice we divide this distribution into seventeen different quantiles, but for the sake of identifying these parameters we constrain the top quantile to have $\alpha_{17}=0$.

Table 14.4 presents the fitted parameters given this error-components variance structure. Columns (1) and (2) of the table show parameters that vary across years. Estimates of the normalizing constants $\left\{\eta_{t}\right\}$ appear in the first column of this panel, while the "year effects" part of the variance structure, $\left\{v_{t}\right\}$, appears in the second column. Recall from our earlier discussion the interpretation of $\eta_{t}$ as a measure of the aggregate uncertainty at time $t$ - this specification gives us a simple way to check the model, since

Table 14.4 Parameter estimates assuming log-normal relative forecast errors and error-components variance specification

\begin{tabular}{|c|c|c|c|c|}
\hline Year & $\begin{array}{r}\eta_{t} \\
\text { (1) }\end{array}$ & $\begin{array}{l}v_{t} \\
(2)\end{array}$ & $\begin{array}{l}\text { Quantile } \\
\text { (3) }\end{array}$ & $\begin{array}{l}\alpha_{i} \\
(4)\end{array}$ \\
\hline 1986 & 1.0635 & -1.2862 & 0.0139 & -3.5888 \\
\hline 1987 & 1.1295 & -1.1886 & 0.0278 & 0.0009 \\
\hline 1988 & 1.2037 & -1.1411 & 0.0539 & -0.0004 \\
\hline 1989 & 1.0884 & -1.2590 & 0.0800 & 3.8415 \\
\hline 1990 & 1.0463 & -1.1884 & 0.1142 & -0.6764 \\
\hline 1991 & 1.1009 & -1.2512 & 0.1485 & -0.5182 \\
\hline 1992 & 1.1228 & -1.1603 & 0.2280 & -0.0510 \\
\hline 1993 & 1.2187 & -1.1499 & 0.3075 & -0.2359 \\
\hline 1994 & 1.2660 & -1.1199 & 0.4008 & 1.5517 \\
\hline 1995 & 1.2004 & -1.2411 & 0.4940 & 0.0261 \\
\hline 1996 & 1.0926 & -1.2052 & 0.6030 & 0.3490 \\
\hline 1997 & 1.0868 & -1.1026 & 0.7120 & -0.0000 \\
\hline 1998 & 1.0682 & -1.2444 & 0.7756 & 0.0001 \\
\hline 1999 & 1.1003 & -1.2407 & 0.8393 & -0.1229 \\
\hline 2000 & 1.1205 & -1.1694 & 0.9197 & 0.7127 \\
\hline 2001 & 1.1064 & -1.3337 & & \\
\hline$\gamma$ & \multicolumn{4}{|c|}{0.7229} \\
\hline$R^{2}$ & \multicolumn{4}{|c|}{0.4723} \\
\hline
\end{tabular}


$v_{t}$ provides a direct measure of aggregate uncertainty. In this case, the correlation between the two measures is 0.47 , consistent with our expectations.

The primary virtue of this error-components specification of the structure of the variance of relative forecast errors has to do with the simplicity of interpreting estimates of $\alpha_{i}$ and $v_{t}$. In particular, for years in which $v_{t}$ is relatively large, the entire population faces greater risk than usual. At the same time the specification allows for variation in uncertainty by wealth (consumption share); the average household in a quantile for which $\alpha_{i}$ is negative faces less uncertainty in an average year than do the very wealthiest households, while the average household in a quantile with $\alpha_{i}$ greater than zero faces more.

Turning our attention to differences in the uncertainty faced by households across the distribution, consider columns (3) and (4) of table 14.4. Here we see that the households in the bottom quantile that collectively consume 1.4 percent of the aggregate face the least uncertainty, with a quantile fixed effect of -3.59 . However, households in the 5-8 percent quantile face the most, with an estimated quantile fixed effect of 3.84. Eight of the consumption share quantiles bear more uncertainty than does the topmost quantile, while seven bear less.

At this point let us pause a moment to be careful about what is meant by "uncertainty" above. Differences in the parameters $\left\{v_{t}\right\}$ across time or $\left\{\alpha_{i}\right\}$ across quantiles are really just related to the standard deviation of the relative forecast errors $\varepsilon_{i t}$. These relative forecast errors have numerous desirable properties, but they do not have a straightforward interpretation either in terms of the welfare costs of uncertainty or in terms of variation in quantities that might be observable. In particular, the distribution of $\varepsilon_{i t}$ depends both on households' risk preferences (here $\gamma$ ) and on the distribution of consumption growth, making it critical to estimate $\gamma$ and the variance structure of the forecast errors simultaneously. In the present case, the estimated value of the coefficient of relative risk aversion is 0.723 . This is on the low end of the range of estimates of this parameter in the microeconometric literature, but it does not seem obviously wrong.

To get a sense of the magnitude of the risk facing individual households, we use the parameters reported in table 14.4 to estimate the risk facing the average household at selected consumption-share quantiles in figure 14.3. To construct this figure we have started with estimates of the measure of risk given by equation (16), but rather than reporting the welfare loss due to uncertainty in utils (which may be difficult to interpret), we have computed the growth rate of aggregate consumption expenditures that would be just enough to compensate households for the risk they bear.

In the present case, because we assume constant elasticity of substitution (CES) utility functions future aggregate consumption $\bar{c}_{t+1}$ cancels out of this calculation. Substituting in our estimates of the parameters $\left\{\eta_{t}\right\}$ and 


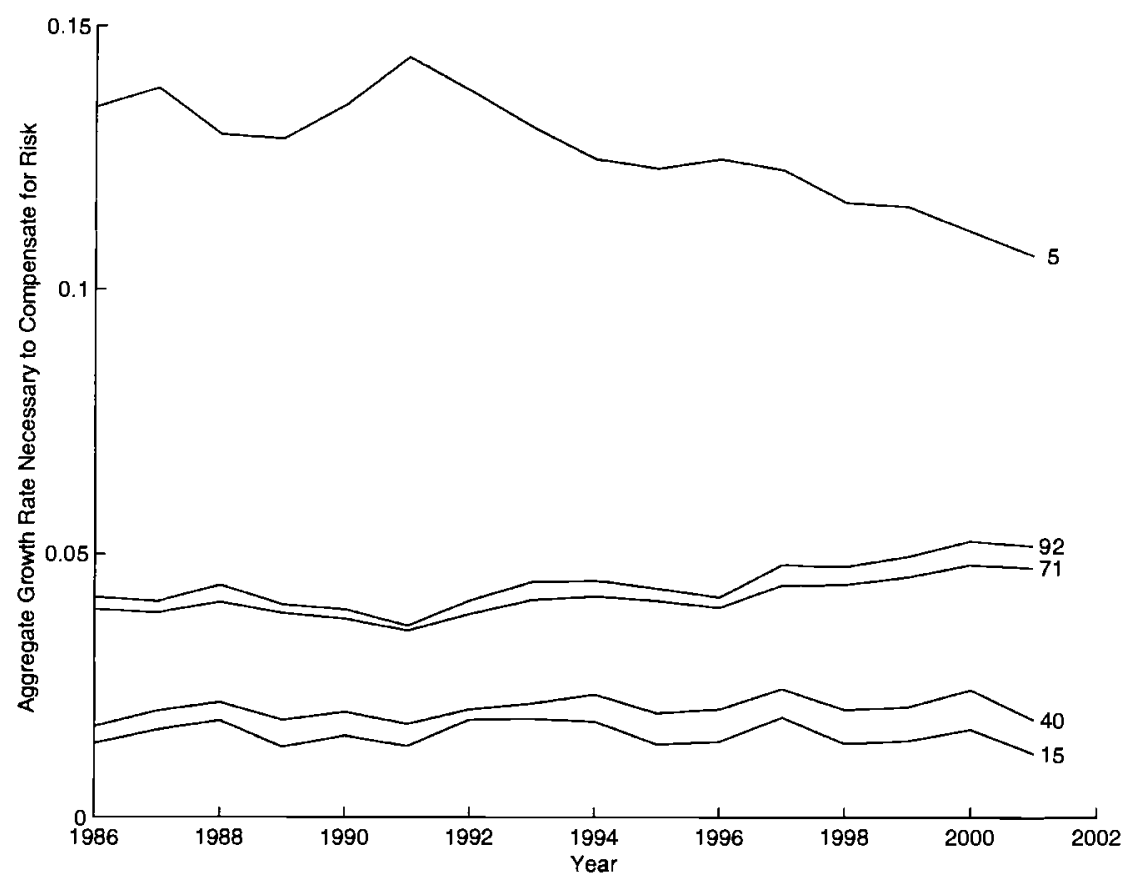

Fig. 14.3 Growth rate necessary to compensate for risk, by quantiles

Notes: Each line indicates the minimum rate of growth necessary to compensate for the risk faced by the average household at the consumption share quantile indicated at the far right. For example, the line labeled " 5 " gives the rate of growth in each year necessary to compensate the average household ex ante at the 5 percent quantile for the risk borne by that household.

of the marginal Markov transition function makes it possible to use a simple line-search algorithm to find the compensating growth rates.

These compensating growth rates are shown for selected consumptionshare quantiles in figure 14.3. Note first that the growth we refer to is the rate of growth in aggregate consumption expenditures for urban households; this quantity grew at an average annual rate of 12 percent over the period 1985-2001. Using the quantity $g_{t}(\sigma)$ as our measure of the welfare loss of uncertainty, the poorest (displayed) quantile of households is much the worst off-from 1985 to 1986 these households would have needed urban expenditures to have grown by nearly 14 percent before they would have preferred the status quo to stagnation and an iron rice bowl. Setting the poorest households aside, risk does increase in a monotone way, with households at the 92 percent quantile requiring compensation that never exceeds 5 percent. Thus, were we to graph it, this measure of risk would display a $\mathrm{U}$ pattern, with the poorest households bearing a great deal of risk, low-income households bearing the least, and risk gradually increasing with consumption shares throughout the rest of the distribution. 
We now turn our attention from risk to inequality. Recall that we're now able to construct estimates of the Markov transition functions. If these functions were invariant across time, it would be a trivial matter to calculate the future evolution of the distribution of consumption for as many periods as we choose, simply by using an estimate of some initial distribution $\Gamma_{0}$, and then applying equation (17) iteratively to trace out future distributions.

Of course, matters are not quite so simple. Instead, we have estimates of the transition function for sixteen different values of $t$, from 1985-2001, and while it's a simple matter to trace out the predicted trajectory over the course of this sample period, this tells us little about future inequality. We adopt the following simple strategy. Given our collection of 16 different estimated transition functions, we simply assume that these functions are representative of the kinds of transition functions which may be realized in the future. Thus, to estimate the evolution of the distribution of consumption over $\tau$ periods we simply make $\tau$ random draws (with replacement) from the collection of transition functions $\left\{\tilde{\Psi}_{t}\right\}$. Starting with the actual distribution of consumption shares in 2001, we substitute these draws sequentially into (17); inverting the resulting function $\Gamma_{t}$ yields an estimate of the Lorenz curve $L_{t}$. Then we use these $\tau$ equations to calculate one possible sample trajectory of the Lorenz curves, which we denote by $\left\{\hat{L}_{t}^{1}\right\}_{t=1}^{\tau}$. We repeat this procedure many times, so that we have a bootstrapped sample of $m$ possible trajectories for the Lorenz curve over time, or $\mathscr{L}=$ $\left\{\left\{\hat{L}_{t}^{i}\right\}_{t=1}^{\tau}\right\}_{i=1}^{m}$.

Now, for any population quantile $x$ we can compute a mean trajectory by computing

$$
\bar{L}_{t}(x)=\frac{1}{m} \sum_{i=1}^{m} L_{t}^{i}(x),
$$

or characterize the distribution of possible trajectories by simply working with the bootstrap sample $\mathscr{L}$.

Figure 14.4 shows values of $\bar{L}_{t}(x)$ for selected values of $x$ (the solid lines), ${ }^{2}$ along with 80 percent confidence intervals, for predicted trajectories beginning in 2001 and running through 2025. The figure has several notable features. First, note that the confidence intervals are very tight, relative to the variation across population quantiles. This is a reflection of a fact already noted above_-differences across households are much more pronounced than differences across time. The very small variation in our estimated "time effects" $\left\{v_{t}\right\}$ and normalizing constants $\left\{\eta_{t}\right\}$ mean that in fact our estimated transition functions don't change very much over time at all; as a consequence it doesn't matter very much what actual sequence of transition functions we draw in our bootstrap exercise.

2. These values are those available in the China Statistical Yearbooks, and are equal to $(0.05,0.1,0.2,0.4,0.6,0.80,0.9)$. 


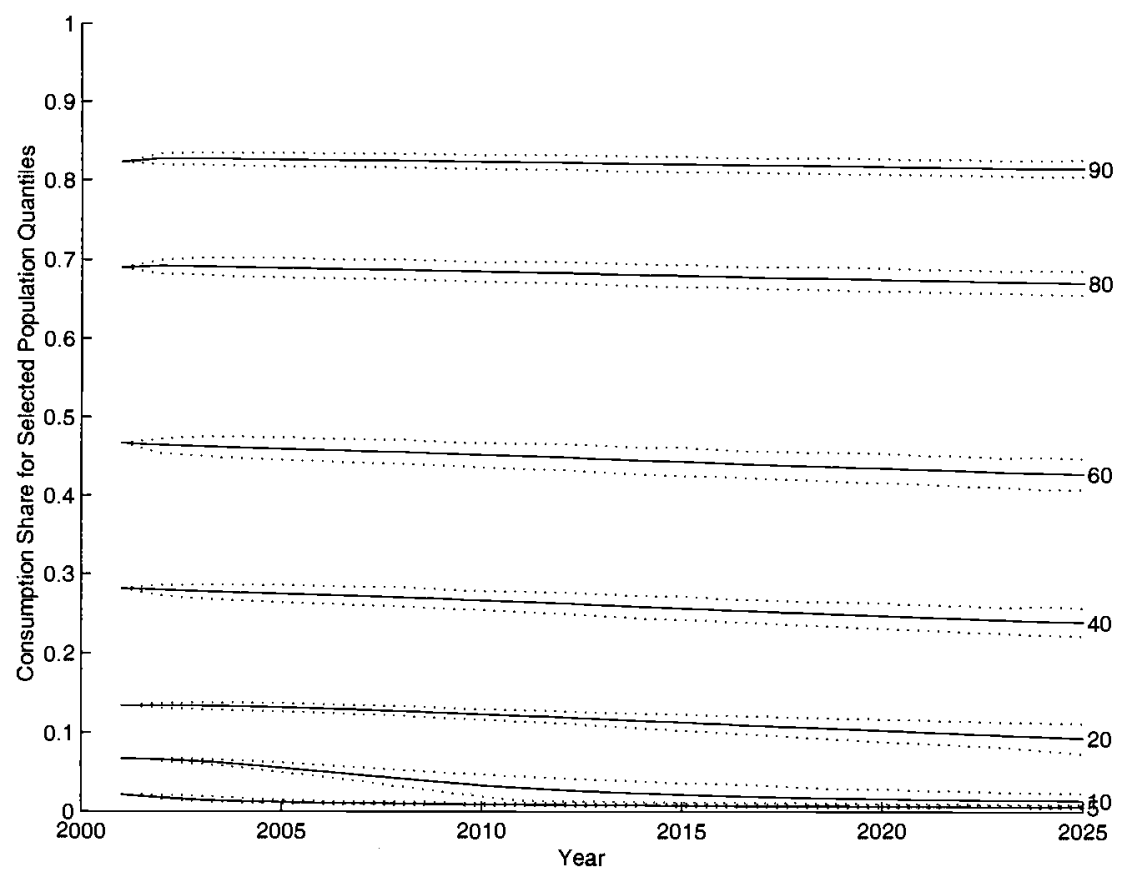

Fig. 14.4 Predicted evolution of consumption shares $L(x)$ for selected population quantiles $x$

Thus emboldened, we henceforth refer to the evolution of $\bar{L}_{t}$. Our estimated model predicts that inequality will continue to increase in China through 2025, but at a relatively slow rate. However, the bottom ten percent of the population will, by then, consume a much smaller share in 2025 ( 2 percent) than at present ( 6.5 percent). Neglecting the welfare costs of risk discussed above, to keep the level of consumption constant for this poorest 10 percent of the population, aggregate urban consumption must grow at an average rate of about five percent to compensate this part of the population whose share is sharply declining. To compensate for risk, of course, much higher growth rates would have to be sustained.

\subsection{Conclusion}

China's economy has changed dramatically over the last two decades, but household level data to understand the effects of China's growth and opening to the outside world are very difficult to come by-data from China's National Bureau of Statistics either have very limited coverage or are very aggregated.

In this paper we make a silk purse of a sow's ear by using aggregate data 
on the distribution of consumption expenditures across (registered) urban households to construct a sequence of Lorenz curves, and then use intertemporal restrictions on individual households' consumption expenditures implied by optimizing behavior by risk-averse households to derive the restrictions on the evolution of these Lorenz curves implied by theory. The evolution of the Lorenz curve turns out to depend on just two kinds of objects: household utility functions, and the distribution of "relative forecast errors" for intertemporally optimizing households.

To pin down household utility, we assume that household preferences exhibit constant relative risk aversion. To pin down the distribution of relative forecast errors we choose a three-parameter log-normal specification, based on an examination of data from a small subset of urban households for which we construct the empirical probability distribution for these relative forecast errors.

For any estimate of the coefficient of relative risk aversion and parameters governing the distribution of relative forecast errors, we are able to predict a sequence of future Lorenz distributions. We compare this predicted trajectory with the actual sequence of distributions realized between 1986 and 2001, choosing our preference and distributional parameters so as to minimize a measure of the distance between these sequences of Lorenz curves.

We present two major empirical findings. First, the risk (ex ante welfare loss due to variation in future consumption) borne by households depends much more on households' resources than it does on the year-even though there are enormous changes in China's aggregate economy over this period, idiosyncratic risk is much more important than any aggregate shock in determining household welfare and in determining evolution of inequality over time.

Second, our estimates of the law of motion governing the Lorenz curves for urban China allow us to make predictions about future consumption inequality. Looking at the entire distribution, we predict that most of the increase in inequality between 1985 and 2025 has already occurred; however, we also predict that the share of consumption accruing to the poorest decile of these households will continue to fall at a relatively rapid rate, lowering the share of consumption for these households from 6.5 percent in 2001 to only 2 percent in 2025.

\section{Appendix A}

\section{A Model with Idiosyncratic Risk}

In this section we describe a model in which households can exchange debt in competitive credit markets, and derive restrictions on the evolution of 
each household's share of aggregate consumption. The key assumptions we exploit are that households all have similar preferences featuring constant relative risk aversion and that all households have access to credit on the same terms. Note that this latter assumption is weaker than assuming that credit markets are perfect - in particular, it may be the case that at the interest rates faced by households for some reason credit markets fail to clear.

Consider, then, an environment with $n$ infinitely lived households. We index these households by $i=1,2, \ldots, n$. Time is discrete and is indexed by $t$. Household $i$ derives momentary utility from consumption according to some function $u_{i}: \mathbb{R} \rightarrow \mathbb{R}$, and discounts future utility at a common rate $\beta \in(0,1)$.

\section{Intertemporal Restrictions}

At any date $t$, household $i$ can exchange claims to consumption at $t+1$ with other households at a price $1 / \rho_{t}$, solving the problem

$$
\max _{b_{i t}} u_{i}\left(c_{i t}-\frac{b_{i t}}{\rho_{t}}\right)+\beta \mathrm{E}_{t}\left[u_{i}\left(c_{i t+1}+b_{i t}\right)+\sum_{j=2}^{\infty} \beta^{j-1} u_{i}\left(c_{i t+j}\right)\right],
$$

where $\mathrm{E}_{t}$ denotes the expectations operator conditional on information available at time $t, b_{i t}$ denotes the debt issued by the household at time $t$, and $c_{i t}$ denotes the household's time $t$ consumption expenditures.

The first-order conditions associated with the household's problem of debt issuance at time $t$ indicate that the household will consume $c_{i t}$ at $t$ if the usual Euler equation

$$
u_{i}^{\prime}\left(c_{i t}\right)=\beta \rho_{t} \mathrm{E}_{t} u_{i}^{\prime}\left(c_{i t+1}\right)
$$

is satisfied.

It is convenient to restrict our attention to the case in which utility functions exhibit constant relative risk aversion, so that

$$
u_{i}\left(c_{i t}\right)=\frac{c_{i t}^{1-\gamma}-1}{1-\gamma},
$$

where $\gamma$ is the coefficient of relative risk aversion. In this case, equation (12) implies that

$$
\left[\beta \rho_{t}\right]^{-1}=\mathrm{E}_{t}\left(\frac{c_{i t+1}}{c_{i t}}\right)^{-\gamma}
$$

for all $i=1, \ldots, n$ and all $t$. As a consequence, we have

$$
\mathrm{E}_{t}\left(\frac{c_{i t+1}}{c_{i t}}\right)^{-\gamma}=\frac{1}{n} \sum_{j=1}^{n} \mathrm{E}_{t}\left(\frac{c_{j t+1}}{c_{j t}}\right)^{-\gamma} .
$$

We can interpret this as a prediction that with the ability to freely exchange debt all households will have the same expected growth in their marginal utilities of consumption. 
Because we want to understand the links between intertemporal restrictions on consumption such as equation (14) and the evolution of inequality, we'll translate equation (14) into a statement about shares of consumption expenditures. Let $\bar{c}_{t}=\sum_{i=1}^{n} c_{i t}$ denote aggregate consumption expenditures at $t$, and $\sigma_{i t}=c_{i t} / \bar{c}_{t}$ denote $i$ 's share of expenditures at $t$. Then

$$
\mathrm{E}_{t}\left\{\left[\left(\frac{\sigma_{i t+1}}{\sigma_{i t}}\right)^{-\gamma}-\frac{1}{n} \sum_{j=1}^{n}\left(\frac{\sigma_{j t+1}}{\sigma_{j t}}\right)^{-\gamma}\right]\left(\frac{\bar{c}_{t+1}}{\bar{c}_{t}}\right)^{-\gamma}\right\}=0 .
$$

Let

$$
\varepsilon_{i t+1} \equiv\left[\left(\frac{\sigma_{i t+1}}{\sigma_{i t}}\right)^{-\gamma}-\frac{1}{n} \sum_{j=1}^{n}\left(\frac{\sigma_{j t+1}}{\sigma_{j t}}\right)^{-\gamma}\right]\left(\frac{\bar{c}_{t+1}}{\bar{c}_{t}}\right)^{-\gamma}
$$

denote household $i$ 's time $t$ forecast error relative to the average forecast error. Note from the properties of equation (15) that $\mathrm{E}_{t} \varepsilon_{i t+1}=0$, as is usual when evaluating forecast errors from Euler equations. However, as Chamberlain (1984) points out, in the usual analysis there may be an aggregate shock that induces correlation across households' forecast errors in the cross section, so that there is no guarantee that realized forecast errors at $t+1$ will in fact average to zero. We've avoided this problem here by eliminating $\rho_{t}$; for us $1 / n \sum_{j=1}^{n} \varepsilon_{j t}=0$ by construction.

\section{Risk}

The uncertainty facing any individual household with consumption share $\sigma_{i t}$ at time $t$ that may reduce its utility at time $t+1$, then, can be summarized by three random variables. The first of these just has to do with variation in the growth of aggregate consumption, $g_{t+1} \equiv \bar{c}_{t+1} / \bar{c}_{t}$. The second represents household-specific surprises that may change the household's share of aggregate expenditures, $\epsilon_{i t}$. Third and finally, the aggregate of surprises facing all other households may change the distribution of resources, $\eta_{t+1} \equiv 1 / n \sum_{j=1}^{n}\left[\left(\sigma_{j t+1} / \sigma_{j t}\right]\right.$.

Define the idiosyncratic risk borne by the household at time $t$ to be the ex ante loss in expected utility at $t+1$ due solely to variation in the purely idiosyncratic shock $\varepsilon_{i t+1}$, or

$$
R_{i t} \equiv u_{i}\left(\bar{c}_{t+1} \sigma_{i t}\right)-\mathrm{E}\left[u_{i}\left(c_{i t+1}\right) \mid I_{t}, \eta_{t+1}, g_{t+1}\right]
$$

where $I_{t}$ denotes the information set at time $t$. Here the first term is the utility the household would obtain at $t+1$ if the household's share of expenditures was unchanged (as would be the case if no household faced any idiosyncratic risk) and the household knew in advance what aggregate consumption would be in $t+1$. The second term is the utility the household would expect if it somehow knew in advance what the realization of all the relevant aggregate random variables would be, so that it remained ignorant only of the idiosyncratic shocks it would experience in the first period.

In a world with complete markets and the assumed CES preferences we 
work with here, it's easy to establish that each household's share of aggregate consumption will remain constant, eliminating all idiosyncratic risk. Thus, we can interpret the first term of equation (16) as the utility the household would obtain if no households bore any idiosyncratic risk less the expected utility of consumption when the household does bear this idiosyncratic component of risk. It is trivial to establish that this cardinal measure of risk is uniquely consistent (up to a linear transformation of $u_{i}$ ) with the notion of increasing risk defined by Rothschild and Stiglitz (1970). Because our measure of idiosyncratic risk is denominated in utils, it is straightforward to construct a variety of useful measures of the welfare loss associated with this risk.

Let $\Psi_{t}\left(\sigma_{i t+1} \mid \sigma_{i t}, x_{i t}, g_{t+1}, \eta_{t+1}\right)$ denote the time $t$ Markov transition function for the household's share $\sigma$ given household characteristics $x_{i t}$ and knowledge of the aggregate quantities $g_{t+1}$ and $\eta_{t+1}$. Then the expression for household $i$ 's time $t$ idiosyncratic risk, as defined above, may be written

$$
R_{i t}=u_{i}\left(\bar{c}_{t+1} \sigma_{i t}\right)-\int u_{i}\left(\bar{c}_{t+1} \sigma^{\prime}\right) d \Psi_{t}\left(\left.\sigma^{\prime}\right|_{\sigma_{i t}}, x_{i t}, g_{t+1}, \eta_{t+1}\right) .
$$

Note that idiosyncratic risk can depend on both household characteristics $x_{i t}$ and on the household's current position in the consumption distribution, $\sigma_{i t}$. Let the distribution of characteristics $x$ of households having a share $\sigma$ of aggregate consumption time $t$ be given by $G_{t}(x \mid \sigma)$. Then to calculate average idiosyncratic risk of households with share $\sigma$ we integrate out the characteristics $x$, obtaining the marginal Markov transition function $\tilde{\Psi}_{t}\left(\sigma^{\prime} \mid \sigma, g_{t+1}, \eta_{t+1}\right)=\int\left(\sigma^{\prime} d \Psi_{t}\right) d G_{t}(x \mid \sigma)$.

Let the distribution of $\sigma$ at $t$ be given by $\Gamma_{t}(\sigma)$; this is the inverse of the Lorenz curve. Average idiosyncratic risk is then given by

$$
R_{t}=\int u_{i}\left(\bar{c}_{t+1} \sigma\right) d \Gamma_{t}(\sigma)-\int u_{i}\left(\bar{c}_{t+1} \sigma^{\prime}\right) d \tilde{\Psi}_{t}\left(\sigma^{\prime} \mid \sigma, g_{t+1}, \eta_{t+1}\right) d \Gamma_{t}(\sigma) .
$$

\section{Distribution}

The Markov transition function $\Psi$, which is critical for calculating average risk in the population, is also critical for understanding how the distribution of resources changes over time. In particular, the inverse Lorenz curves $\left\{\Gamma_{t}\right\}$ satisfy a law of motion

$$
\Gamma_{t+1}(\hat{\sigma})=\int_{\left\{\sigma^{\prime}<\hat{\sigma}\right\}} d \tilde{\Psi}_{t}\left(\sigma^{\prime} \mid \sigma, g_{t+1}, \eta_{t+1}\right) d \Gamma_{t}(\sigma) .
$$

Accordingly, knowledge of the transition functions $\tilde{\Psi}_{t}$ suffices to characterize both average risk and the evolution of inequality in the population.

\section{Forecast Errors and Markov Transitions}

Recall that an individual household's uncertainty depends only on relative forecast errors $\varepsilon_{i t+1}, \eta_{t+1}$, and on $g_{t+1}$. In particular, we can use equation (15) to express $\tilde{\Psi}_{t}$ in terms of the distribution of relative forecast errors in 
the population. Let $\varepsilon_{i t+1}$ have the cumulative probability distribution $F_{t}\left(\varepsilon \mid \sigma_{i t}, x_{i t}\right)$. Then note from equation (15) that we have

$$
\sigma_{i t+1}=\sigma_{i t}\left(g_{t+1}^{\gamma} \varepsilon_{i t+1}+\eta_{t+1}\right)^{-1 / \gamma},
$$

so that

$$
\tilde{\Psi}_{t}\left(\sigma^{\prime} \mid \sigma, g_{t+1}, \eta_{t+1}\right)=\iint_{\left\{\varepsilon>\left[\left(\sigma / \sigma^{\prime}\right)^{\gamma}-\eta_{t+1}\right] / g_{t+1}^{\gamma}\right\}} d \tilde{F}_{t}(\varepsilon \mid \sigma, x) d G_{t}(x \mid \sigma) .
$$

Let $\tilde{F}_{t}(\varepsilon \mid \sigma)=\int d F_{t}(\varepsilon \mid \sigma, x) d G_{t}(x \mid \sigma)$ denote the marginal distribution of relative forecast errors $\varepsilon$ for households having consumption share $\sigma$. Then, because time $t+1$ shares must integrate to 1 , we have the adding-up restriction

$$
\int \sigma\left(\eta_{t+1}+\varepsilon g_{t+1}^{\gamma}\right)^{-1 / \gamma} d \tilde{F}_{t}(\varepsilon \mid \sigma) d \Gamma_{t}(\sigma)=1,
$$

which pins down the value of the $\left\{\eta_{t}\right\}$ in terms of the remaining objects in equation (20). Accordingly, given knowledge of the distributions $\left\{\left(F_{t}, G_{t}\right)\right\}$, the sequence of realized aggregate consumptions to pin down $\left\{g_{t}\right\}$, and the risk aversion parameter $\gamma$, we can completely describe the evolution of inequality and the distribution of risk in the population.

\section{Appendix B}

\section{Estimating Idiosyncratic Risk}

How can we go about using data on the evolution of Lorenz curves to estimate the risk borne by differently situated households? Given our maintained assumption of equal access to credit markets and some initial distribution of consumption shares $\Gamma_{0}$, equation (17) allows us to trace out changes in the distribution over time given knowledge of the Markov transition functions $\left\{\tilde{\Psi}_{t}\right\}$ and of the sequence $\left\{g_{t}, \eta_{t}\right\}$. However, each $\left\{\Psi_{t}\right\}$ must be consistent with the law of motion for shares in equation (18), while the unknown sequence $\left\{\eta_{t}\right\}$ is determined by the adding-up restriction in equation (20). As a consequence, the extent of our ignorance regarding $\left\{\tilde{\Psi}_{t}\right\}$ amounts to ignorance regarding the risk-aversion parameter $\gamma$ and the marginal distributions of relative forecast errors in each period, $\left\{\tilde{F}_{t}\right\}$.

Although we don't begin with knowledge of the distributions of errors $\left\{\tilde{F}_{t}\right\}$, the first moment of each $\tilde{F}_{t}$ must be equal to zero by equation (12), while the support of the distribution at $t$ must be a subset of $\left[\eta_{t+1} / g_{t+1}^{\gamma}, \infty\right)$. After examining the empirical distribution of estimated relative forecast errors for a small panel of urban Chinese households, it appears that this empirical distribution at $t$ is adequately represented by what Johnson and 
Kotz (1970) call the "three-parameter log-normal distribution," with $\log (\varepsilon$ $\left.+\theta_{t+1}\right)$ distributed $N\left(\mu_{t}(\sigma), v_{t}^{2}(\sigma)\right)$. Of the three parameters $\left(\theta_{t}, \mu_{t}(\sigma), v_{t}(\sigma)\right)$ only two are free, with $\theta_{t}=\eta_{t} / g_{t}^{\gamma}$ - since shares must all lie in the $(0,1)$ interval-and $\mu_{t}=\log \left(\theta_{t}\right)-v_{t}^{2}(\sigma) / 2$ (since the expected value of $\varepsilon$ must be zero).

With these restrictions on the distribution of relative forecast errors, the only things that remain for us to infer from data are the coefficient of relative risk aversion $\gamma$ and the scale parameters $\left\{v_{t}(\sigma)\right\}$. In practice we only work with a finite number (say $n$ ) of share values, and have only a finite number of periods $(T)$ of data on the distribution of consumption. We impose a log-linear structure on these scale parameters, assuming that for every year $t=1, \ldots, T$ and share $\sigma \in\left\{\sigma_{1}, \ldots, \sigma_{n}\right\}$ there exists an $\ell$-vector of observable variables $x_{i t}$ that determines the scale parameters via

$$
\log v_{t}\left(\sigma_{i}\right)=\delta^{\prime} x_{i t}
$$

for some $\ell$-vector $\delta$. This assumption allows us to estimate a set of $\ell$ parameters that may be presumed to be smaller than $T n$, and guarantees that estimated values of $v_{t}(\sigma)$ will be positive, as they must be to be interpretable as the standard deviation of a normally distributed variable.

As a consequence of the foregoing, we're left with the problem of estimating $\ell+1$ parameters $b_{0}=\left(\gamma, \delta^{\prime}\right)$. We have data on the share of consumption expenditures for population quantiles $\left(x_{1}, x_{2}, \ldots, x_{m}\right)$ for each of $T+1$ years. We use these data on consumption expenditures to approximate the Lorenz curves $\left\{L_{t}(x)\right\}_{t=1}^{T}$ of expenditure shares. We fix an initial guess of our parameters $b$. Noting that $L_{t}=\Gamma_{t}^{-1}$, conditional on this guess we use the law of motion in equation (17) (along with the adding-up restriction in equation [20], and equation [21]) to predict a sequence of Lorenz curves $\left\{\hat{L}_{t}(x \mid b)\right\}_{t=1}^{T}$. We compute a simple measure of distance between the predicted and actual Lorenz curves

$$
d(b)=\sum_{t=1}^{T} \sum_{i=1}^{m}\left(L_{t}\left(x_{i}\right)-\hat{L}_{t}\left(x_{i} \mid b\right)\right)^{2}
$$

and then use a simplex minimization routine to find the value $\hat{b}=$ $\operatorname{argmin}_{b} d(b)$.

\section{References}

Amemiya, T. 1984. Tobit models: A survey. Journal of Econometrics 24 (1-2): 3-61. Arrow, K. J. 1964. The role of securities in the optimal allocation of risk bearing. Review of Economic Studies 31:91-96.

Benjamin, D., L. Brandt, and J. Giles. 2005. The evolution of income inequality in rural China. Economic Development and Cultural Change 53 (4): 769-824. 
Bhalla, A. S., S. Yao, and Z. Zhang. 2003. Causes of inequalities in China. Journal of International Development 15:939-55.

Chamberlain, G. 1984. Panel data. In Handbook of econometrics, ed. Z. Griliches and M. D. Intriligator, 1247-1318. Amsterdam: North-Holland.

Chen, S., and M. Ravallion. 2004. Household welfare impacts of WTO accession in China. World Bank Economic Review 18 (1): 29-58.

Deaton, A., and C. Paxson. 1994. Intertemporal choice and inequality. Journal of Political Economy 102 (3): 437-67.

Johnson, N. L., and S. Kotz. 1970. Continuous univariate distributions-1. New York: Wiley.

Kahn, A. R., and C. Riskin. 2001. Inequality and poverty in China in the age of globalization. Oxford, UK: Oxford University Press.

Kanbur, R., and X. Zhang. 2005. Fifty years of regional inequality in China: A journey through central planning, reform, and openness. China Economic Review 16:189-204.

Ligon, E., and L. Schechter. 2003. Measuring vulnerability. Economic Journal 113 (486): C95-C102.

Lucas, R. E., Jr. 1992. On efficiency and distribution. Economic Journal 102:233-47.

Milanovic, B. 2005. Can we discern the effect of globalization on income distribution? Evidence from household surveys. World Bank Economic Review 19 (1): 21-44.

Ravallion, M. 2004. Looking beyond averages in the trade and poverty debate. World Bank Policy Research Paper no. 3461. Washington, DC: World Bank.

Ravallion, M., and S. Chen. 2004. China's (uneven) progress against poverty. World Bank Policy Research Working Paper no. 3408. Washington, DC: World Bank, September.

Rothschild, M., and J. E. Stiglitz. 1970. Increasing risk, I: A definition. Journal of Economic Theory 2:225-43.

Storesletten, K., C. I. Telmer, and A. Yaron. 2004. Consumption and risk sharing over the life cycle. Journal of Monetary Economics 51 (3): 609-33.

Wilson, R. 1968. The theory of syndicates. Econometrica 36 (January): 119-32.

Yang, D. L. 1997. Beyond Beijing: Liberalization and the regions in China. New York: Routledge.

Yao, S., and Z. Zhang. 2001. On regional inequality and diverging clubs: A case study of contemporary China. Journal of Comparative Economics 29:466-84.

Zhang, X., and K. H. Zhang. 2003. How does globalization affect regional inequality within a developing country? Evidence from China. Journal of Development Studies 30 (4): 47-67.

\section{Comment Shang-Jin Wei}

This is a sophisticated paper. An important contribution of the paper is methodological in nature. Deaton and Paxson (1994) and other papers in the literature on income inequality have provided theoretical justification for an empirical specification on household panel data. However, a com-

Shang-Jin Wei is assistant director and chief of the trade and investment division at the International Monetary Fund, a senior fellow at the Brookings Institution, and director of the National Bureau of Economic Research's working group on the Chinese Economy. 
mon data constraint that empirical researchers face is that only repeated cross sections are available, rather than a true panel. This is the case for the data on Chinese urban income that Ethan Ligon is working with. In this paper, Ligon provides a methodology that can be applied to such data sets. Specifically, by integrating the intertemporal restrictions on individual household consumption, he derives a law of motion for the distribution of consumption across households at a given point in time. While such a specification cannot exploit all the information from a panel household data set if one exists, it allows researchers to work with more commonly available (and less demanding) data sets on repeated cross sections of households.

As to possible areas for improvement, I would propose two. First, it seems possible that some of the key inferences may be driven by noise rather than information. More robustness checks may be helpful. Second, conceptually, the paper does not quite address the key question in the theme of the conference, namely, the impact of globalization on inequality or poverty. Indeed, it does not quite address the question implied in the title of the paper-the impact of globalization on China's inequality. Let me discuss these two comments in turn.

The first comment has to do with noise versus information in the empirical inferences in the paper. The estimates are presented in table 14.1. As an example, one can look at the estimates of the alphas - the estimated excess uncertainty an average household in a given quantile faces relative to the very wealthiest households in the sample. (The author divides the households into seventeen bins by their income levels.) Which households face the greatest uncertainty? According to table 14.1, the top five are those in the 4th, 9th, 15th, 11th, and 10th quantiles. Which households face the least uncertainty? Table 14.1 says that the top five are those in the 1st, 5th, 6 th, 8th, and 14th quantile. Why do we observe so much fluctuation in the ranks? Since the number of bins into which one classifies households is somewhat arbitrary, how robust is the inference to alternative classifications? Another set of key parameters is the etas. They are within the range of $[1.04,1.26]$. Can we reject the null that they are all the same? We don't know. To summarize the comments so far, before we can conclude which inferences are robust and which are fragile, it would be useful to perform more perturbations of the basic specification and more statistical tests.

A potentially more serious shortcoming with working with repeated cross sections is what I call a "shifting base" problem that could render the resulting inferences invalid and misleading. Recall that the paper makes inferences on the relative rank of risks that urban households face as a function of their income in the distribution. An important assumption is that the underlying distribution of the households stays the same even though in any different year a different cross section of households gets surveyed. However, over the period of the sample (1986-97), there may have been systematic migration from the relatively poor rural areas to relatively welloff urban areas. In addition, administrative units that were previously clas- 
sified as rural counties have been gradually reclassified as cities (and the households residing there reclassified as urban households). These facts imply that the true characters of the households in any given income bin may change from year to year in the sample. Inferences based on an assumption of a fixed household character may be misleading (especially when the risk ranks jump around in table 14.1).

My second comment has to do with the theme of the conference- the impact of globalization on income inequality or poverty, which Ligon's paper alludes to in the title but does not directly address. Which part of change in the Chinese household income over the recent past can be attributed to China's greater exposure to international trade (and other dimensions of globalization)? The answer cannot be inferred from the statistical table and figures in the current paper.

To start with, let me note the temptation to conclude that globalization has increased the inequality: China's exposure to trade and FDI openness has increased greatly (from a trade-GDP ratio of 5 percent in 1980 to about 35 percent now). At the same time, income inequality as measured by the Gini coefficient has risen dramatically. This has led some observers to draw the conclusion that globalization has increased the inequality.

Of course, association does not imply causation. Moreover, inequality is a function of many factors. If one could isolate the effect of trade globalization, what is its effect on China's household income inequality? This is the question that $\mathrm{Yi} \mathrm{Wu}$ and I have looked at. Working with a combination of household data sets and a data set of urban and rural average incomes, we decompose the question into three parts: the impact of trade openness on the within-rural income inequality, the within-urban inequality, and the inequality between urban and rural areas. We find evidence that trade globalization reduces within-rural inequality, raises the within-urban inequality (by a moderate amount), and reduces the rural-urban inequality (by a significant amount). Combining the three findings, we find that greater trade openness has led to a moderate decline (rather than an increase) in household income. If one is interested in reducing income inequality in China, the right approach would not be to reduce the degree of openness of the already open areas but to speed up the opening-up of currently less open regions.

I learned much from Ligon's paper. If the author could work with a true panel data set and offer more statistical tests, readers' confidence in the inference could be enhanced.

\section{Reference}

Deaton, A., and C. Paxson. 1994. Intertemporal choice and inequality. Journal of Political Economy 102 (3): 437-67.

Wei, S.-J., and Y. Wu. 2004. "Trade openness and income equality: the case of China," working paper, IMF. 
